\title{
Designing High Reflectivity Omnidirectional Coating of Mirrors for Near Infrared Spectrum (700-2500 nm)
}

\author{
Shireen Mohammed Abed ${ }^{1} \&$ Saeed Naif Turki Al-Rashid ${ }^{1}$ \\ ${ }^{1}$ Physics Department, Education College for Pure Sciences, Anbar University, Anbar, Iraq \\ Correspondence: Shireen Mohammed Abed, Physics Department, Education College for Pure Sciences, Anbar \\ University, Anbar, Iraq. E-mail: sh_82_2006@hotmail.com
}

Received: August 21, 2012 Accepted: September 10, 2012 Online Published: January 16, 2013

doi:10.5539/apr.v5n1p102 URL: http://dx.doi.org/10.5539/apr.v5n1p102

\begin{abstract}
In this paper, a high reflection coating is designed depending on the variable of refractive indices for NIR spectral region $(700-2500 \mathrm{~nm})$ by the use of the computer program MATLAB version 7 . We could find the reflective $99.62 \%$ for seven layers at the incident angels $\left(90^{\circ}, 40^{\circ}\right)$ in the wavelength $(1064 \mathrm{~nm})$ for coatings $(\mathrm{Si}$, $\mathrm{MgF}_{2}$ ), substrata BK7 (relatively hard borosilicate crown glass with high homogeneity), which is used for laser application such as the ND:YAG laser $(1060 \mathrm{~nm})$, and $\mathrm{R}=98.37 \%$ for coatings $\left(\mathrm{SbSe}, \mathrm{Na}_{3} \mathrm{AIF}_{6}\right)$ and substrata glass for eleven layers at $\theta=90^{\circ}$ which covers the wavelength from $(955.6 \mathrm{~nm})$ to $(1622 \mathrm{~nm})$ and represents the complete range for optical telecommunication band (short (S) $1460-1530 \mathrm{~nm}$, conventional (C) 1530-1560 nm and long (1) 1560-1620 nm). The results show that the reflectivity of the stack increases with the number of layers in the stack, the best layer number is nine which has a reflective of $99.62 \%$ at $(1060 \mathrm{~nm})$, as shown in Figure 4a. Also the reflective changes with incident angel; the best angel is $\left(40^{\circ}\right)$ which gives the convergent reflective for electric and magnetic polarization $99.91 \%$ and $99.36 \%$, respectively for the wavelength $(1060 \mathrm{~nm})$.
\end{abstract}

Keywords: designing, coating, reflectivity, near infrared

\section{Introduction}

Infrared waves are electromagnetic waves with frequencies lower than visible light. The lowest frequencies of visible light are red, so one call the lower frequencies infrared, meaning beyond red. This type of electromagnetic radiation is widely used for local communications (Daniel et al., 1996). The IR spectral region of the electromagnetic spectrum extends from the red end of the visible spectrum to the microwave region; it includes radiation with wave numbers ranging from about 14,000 to $20 \mathrm{~cm}^{-1}$, or wavelengths from 700 to $50000 \mathrm{~nm}$. The near-IR (NIR) region extends from the visible region at $(700 \mathrm{~nm})$ to the mid-IR region at $(2500 \mathrm{~nm})$ (Michele et al., 1995).

When the electromagnetic wave is incident on plane surface bonding two substances of indices $\mathrm{n}$ and $\mathrm{n}^{-}$, this wave suffer absorption, reflection, dispersion and transmittance, according to Equation (1), as shown in Figure 1 (Stenzel, 2005):

$$
\mathrm{T}+\mathrm{R}+\mathrm{A}+\mathrm{S}=1
$$




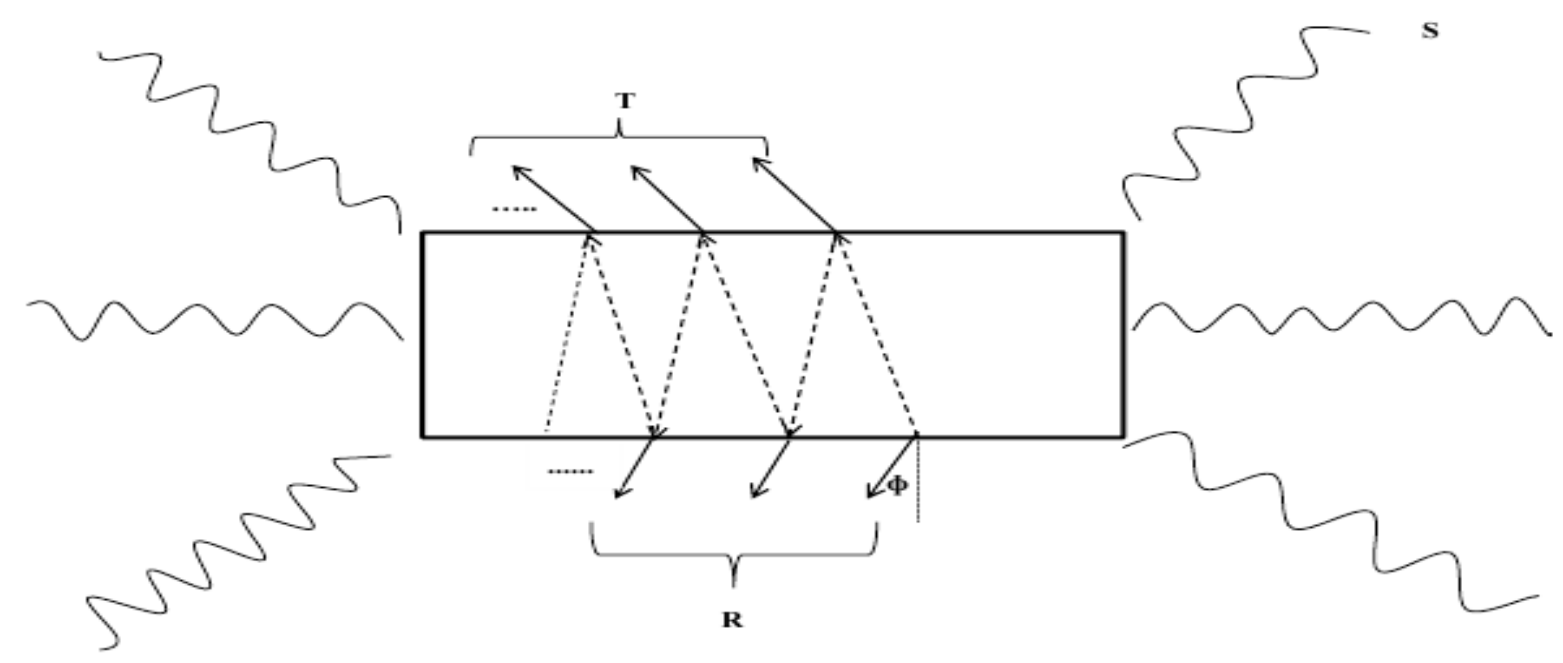

Figure 1. The definitions of T, R, and S. $\phi$ are the incidence angle (Stenzel, 2005)

Where transmittance is $\mathrm{T}$, the specula reflectance $\mathrm{R}$, the optical scatter $\mathrm{S}$, the absorptions $\mathrm{A}$, as conservation of energy. But as we work with homogenous materials and flat surfaces, scatter does not occur and Equation (1) becomes (Stenzel, 2005):

$$
\mathrm{T}+\mathrm{R}+\mathrm{A}=1
$$

Multilayer optical thin film coating has extensively been used for reflectivity modulation in various optical and optoelectronic components (Kheraj et al., 2008). It's has a wide range of applications, such as displays; applications of near-infrared, such as camera lenses, mirrors, and filters; eyeglasses; mirrors, laser windows, and polarizes; optics of photocopiers and compact disks; optical communications; home appliances, such as heat reflecting oven windows ((Kheraj et al., 2008; Sophocles, 2010)

Multilayer optical thin film coating include anti reflection (AR) and high reflection (HR) coating on leaser diode facets (Kheraj et al., 2008). Laser and fabry-perot resonators require high reflectivity that is unattainable from metallic films which also suffer from high absorption in a lesser degree (Sharma, 2006). AR coating is used on lenses of camera and telescope and fabrication of polarizing beam splitters and various optical filters (Kheraj et al., 2008).

The main interest in dielectric mirrors is that they have extremely low losses at optical and infrared frequencies, as compared to ordinary metallic mirrors. On the other hand, metallic mirrors reflect over a wider bandwidth than dielectric ones and from all incident angles. A dielectric mirror consists of identical alternating layers of high and low refractive indices, as shown in Figure 2(a). The optical thicknesses are typically chosen to be quarter-wavelength long, $\mathrm{n}_{\mathrm{H}} \mathrm{l}_{\mathrm{H}}=\mathrm{n}_{\mathrm{L}} \mathrm{l}_{\mathrm{L}}=\frac{\lambda_{\mathrm{o}}}{4}$ at some operating wavelength $\lambda_{0}$ (center wavelength). The standard arrangement is to have an odd number of layers, with the high index layer being the first and last layer (Sophocles, 2010).

The Fresnel amplitude reflection coefficient (r) for an interface between two Non-absorbing media at normal incidence can be represented by the following equation (Ronald, 2002):

$$
r=\frac{n_{1}-n_{2}}{n_{1}+n_{2}}
$$

where $n_{1}$ and $n_{2}$ are the (real) indices of refraction of the two media. For the more general case of absorbing media with complex refractive indices $n j=n j-i k j(j=1,2, \ldots$.$) the reflection intensity coefficient (\mathrm{R})$ is the amplitude reflection coefficient (r) times its complex conjugate $\left(\mathrm{r}^{*}\right)$ (Wwillely, 2002):

$$
\mathrm{R}=\mathrm{rr} *
$$

Lusk and Placido (2005), used thin-film $\mathrm{SiO}_{2}$ and $\mathrm{Si}$ as coating and glass as the substrate and got the reflectivity $\mathrm{R}=99.5 \%$ at a design wavelength $1540 \mathrm{~nm}$ for 14 layers. AL-Dujely Wasfi Hammed Rasheed (2000) used 
thin-film $\mathrm{ZnS}, \mathrm{MgF}_{2}$ as coating and $\mathrm{BK} 7$ as the substrate and he got the reflectivity $\mathrm{R}=82.5 \%$ at a design wavelength $1060 \mathrm{~nm}$ for five layers. Kherj, Panchal, Desai and Potbhare (2008) used thin-film $\mathrm{AL}_{2} \mathrm{O}_{3}$ and $\mathrm{Si}$ as coating and GaAs as the substrate and got the reflectivity $\mathrm{R}=98.66 \%$ at a design wavelength $890 \mathrm{~nm}$ for four layers. Kohoutek et al. (2009) used thin-film GeS and SbSe as coating and $\mathrm{SiO}_{2}$ as the substrate and got the reflectivity $\mathrm{R}=98.8 \%$ at a design wavelength $1550 \mathrm{~nm}$ for 15 layers.

In our work, we will design a computer program to calculate and optimize the reflectivity as a function of wave length for near IR spectrum $(700-2500 \mathrm{~nm})$, for different dielectric materials and we will see the effect of substrate, number of layers and incident angle of NIR rays on reflectivity of these materials.

\section{Theoretical Basis}

The multilayer optical coating usually consists of a stack of several layers of non-absorbing dielectric materials with different refractive indices (Kheraj et al., 2008). The all-dielectric multilayer coating can achieve high reflectivity with minimal scattering and absorption losses (Sharma, 2006)

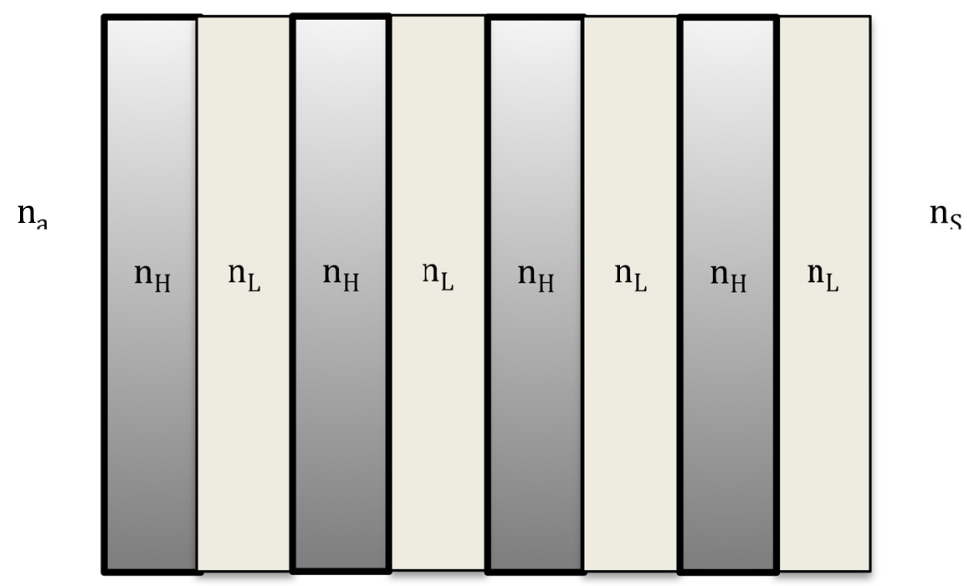

Figure. 2a. Stack of alternate high and low refractive index quarter-wave layers for high reflectance applications (Sharma, 2006)

Suppose that a plane electromagnetic wave with wave-vector $\mathrm{K}$ and electric field amplitude $\mathrm{E}_{0}$ is incident on a plane surface separating isotropic media with refractive indices $n_{1}$ and $n_{2}$. The angle of incidence between the incident wave-vector $\mathrm{k}$ and the normal to the surface $\hat{\mathrm{n}}$ isîor $\theta$. Without loss of generality, one can separately treat the two cases where the incident vector $E$ lies in the plane defined by $\mathrm{k}$ and $\hat{\mathrm{n}}$, denoted by || . Other names which are commonly used for || are P or TM (transverse magnetic), and that where $\mathrm{E}$ is normal to this plane, denoted by $\perp$ (other names S or TE (transverse electric) (Lipson et al., 2010).

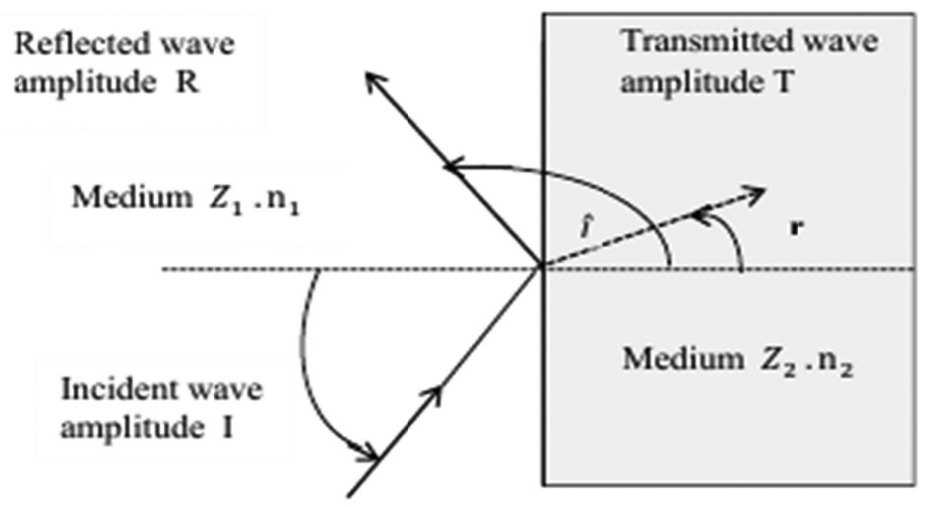

Figure 2b. The Incident, reflected and transmitted waves (Lipson et al., 2010) 
Figure $2 \mathrm{~b}$ shows the geometry of this situation. Notice that reflected and transmitted waves have been introduced. The plane containing the incident wave-vector $\mathrm{k}$, the reflected and transmitted wave-vector and the normal $\hat{n}$ is the $(\mathrm{x}, \mathrm{z})$ plane, and the vector $\hat{\mathrm{n}}$ is along the $\mathrm{z}$ - direction. We denote the amplitudes (electric field magnitudes) of the incident, reflected and transmitted waves by $\mathrm{I}, \mathrm{R}$ and $\mathrm{T}$ respectively. The magnitudes of the wave-vectors in the two media are $\mathrm{K}_{1}$ and $\mathrm{K}_{2}$ and clearly $\mathrm{k}_{1} / \mathrm{n}_{1}=\mathrm{k}_{2} / \mathrm{n}_{2}=\mathrm{k}_{0}$ since both waves have the same frequency. At normal incidence, the reflection and transmission coefficients for the two polarizations are equal and are given by (Lipson et al., 2010):

$$
\begin{aligned}
& \mathrm{R}=\frac{\mathrm{n}_{1}-\mathrm{n}_{2}}{\mathrm{n}_{1}+\mathrm{n}_{2}}=\frac{1-\mathrm{n}_{\mathrm{r}}}{1+\mathrm{n}_{\mathrm{r}}} \\
& \mathrm{T}=\frac{2 \mathrm{n}_{1}}{\mathrm{n}_{1}+\mathrm{n}_{2}}=\frac{2}{1+\mathrm{n}_{\mathrm{r}}}
\end{aligned}
$$

where $n_{r}$ is the relative refractive index between the two media. We define reflection and transmission coefficients for polarization TE or $\perp$ (denoted by the subscript $\perp$ ) (A. LIPSON et al., 2010):

$$
\begin{aligned}
& \mathrm{R}_{\perp}=\frac{\mathrm{n}_{1} \cos \hat{\imath}-\mathrm{n}_{2} \cos \hat{\mathrm{r}}}{\mathrm{n}_{1} \cos \hat{\imath}+\mathrm{n}_{2} \cos \hat{\mathrm{r}}}=\frac{\cos \hat{\imath}-\mathrm{n}_{\mathrm{r}} \cos \hat{\mathrm{r}}}{\cos \hat{\imath}+\mathrm{n}_{\mathrm{r}} \cos \hat{\mathrm{r}}} \\
& \mathrm{T}_{\perp}=\frac{2 \mathrm{n}_{1} \cos \hat{\imath}}{\mathrm{n}_{1} \cos \hat{\imath}+\mathrm{n}_{2} \cos \hat{\mathrm{r}}}=\frac{2 \cos \hat{\imath}}{\cos \hat{\imath}+\mathrm{n}_{\mathrm{r}} \cos \hat{r}}
\end{aligned}
$$

The coefficients for the | plane of polarization can be worked out similarly (Lipson et al., 2010):

$$
\begin{gathered}
\mathrm{R}_{||}=\frac{\mathrm{n}_{1} \cos \hat{\mathrm{r}}-\mathrm{n}_{2} \cos \hat{\mathrm{r}}}{\mathrm{n}_{1} \cos \hat{\mathrm{r}}+\mathrm{n}_{2} \cos \hat{\imath}}=\frac{\cos \hat{\mathrm{r}}-\mathrm{n}_{\mathrm{r}} \cos \hat{\imath}}{\cos \hat{\mathrm{r}}+\mathrm{n}_{\mathrm{r}} \cos \hat{\imath}} \\
\mathrm{T}_{\perp}=\frac{2 \mathrm{n}_{1} \cos \hat{\mathrm{r}}}{\mathrm{n}_{1} \cos \hat{\mathrm{r}}+\mathrm{n}_{2} \cos \hat{\imath}}=\frac{2 \cos \hat{r}}{\cos \hat{\mathrm{r}}+\mathrm{n}_{\mathrm{r}} \cos \hat{\imath}}
\end{gathered}
$$

These functions are known as Fresnel coefficients (Lipson et al., 2010).

A high reflectance coating can be designed by using dielectric quarter-wave stack of alternate high- and lowrefractive index materials. If $n_{H}$ and $n_{L}$ are the indices of the high- and low-index layers and if the stack is arranged, the high-index layers are outermost at both sides. The transformation matrix for a stack of $\mathrm{N}$ pairs of quarter-wave layers of high and low refractive index materials can be expressed in the form (Sharma, 2006):

where

$$
M=\left(M_{H} M_{L)}^{N}\right.
$$

$$
\begin{gathered}
M_{H}=\left|\begin{array}{cc}
\cos \beta_{H} t_{H} & \left(-\frac{i}{y_{H}}\right) \sin \beta_{H} t_{H} \\
-i y_{H} \sin \beta_{H} t_{H} & \cos \beta_{H} t_{H}
\end{array}\right| \\
M_{L}=\left|\begin{array}{cc}
\cos \beta_{L} t_{L} & \left(-\frac{i}{y_{L}}\right) \sin \beta_{L} t_{L} \\
-i y_{L} \sin \beta_{L} t_{L} & \cos \beta_{L} t_{L}
\end{array}\right|
\end{gathered}
$$

therefore,

where the normal incidence was assumed to be :

$$
\begin{gathered}
M=\left[\left(\begin{array}{cc}
0 & \frac{-i}{y_{H}} \\
-i y_{H} & 0
\end{array}\right)\left(\begin{array}{cc}
0 & \frac{-i}{y_{L}} \\
-i y_{L} & 0
\end{array}\right)\right]^{N} \\
M=\left[\begin{array}{cc}
\left(\frac{-y_{L}}{y_{H}}\right)^{N} & 0 \\
0 & \left(\frac{-y_{H}}{y_{L}}\right)^{N}
\end{array}\right]
\end{gathered}
$$

$$
\beta_{H} t_{H}=\frac{2 \pi}{\lambda_{\mathrm{v}}} n_{H} t_{H}=\pi / 2 \quad \text { for } \lambda_{\mathrm{v}}=\lambda_{\mathrm{o}}
$$




$$
\beta_{L} t_{L}=\frac{2 \pi}{\lambda_{\mathrm{v}}} n_{L} t_{L}=\pi / 2 \quad \text { for } \lambda_{\mathrm{v}}=\lambda_{\mathrm{o}}
$$

where ( $\mathrm{t}$ ) is the thickness, $\beta_{H}=n_{H}\left(\frac{2 \pi}{\lambda}\right) \cos \varphi_{H}$ and $\beta_{L}=n_{L}\left(\frac{2 \pi}{\lambda}\right) \cos \varphi_{L}$ in the process of wave propagation through an $\mathrm{N}$ layer stack. $\mathrm{n}_{\mathrm{H}}, \mathrm{n}_{\mathrm{L}}$ are indices of the high and low index layers, where $\theta, \varphi$ are the angle of reflection and angle of refraction, $y_{0=}{ }^{n_{0}} / \cos \theta, y_{1=}{ }^{n_{1}} / \cos \phi_{1}$, and $y_{s={ }_{s} / \cos \psi}$ as shown in Figure 3 (Sharma,2006).

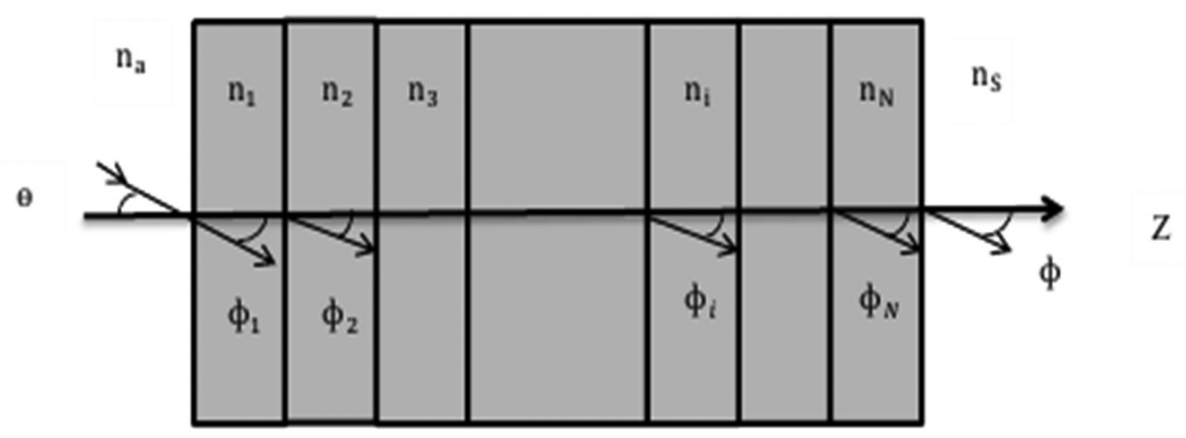

Figure 3. The $\mathrm{N}$ layer stack; $\varphi_{\mathrm{j}}$ and $\mathrm{n}_{\mathrm{j}}$ are the angles of refraction and index of refraction of the jth layer (Sharma, 2006)

The coefficients $y_{L}, y_{H}$ can be calculated for either state of polarization from the knowledge of indices of refraction of the films and angles of refraction in each film. The latter can be obtained from:

$$
n_{0} \sin \theta=n_{1} \sin \phi_{1}=n_{2} \sin \phi_{2=\ldots}=n_{N} \sin \phi_{N}=n_{s} \sin \phi_{N}=n_{s} \sin \psi .
$$

giving the reflectance of the stack as (Sharma, 2006):

$$
\mathrm{R}=r^{2}=\left|\frac{n_{s}\left(\frac{n_{H}}{n_{L}}\right)^{2 N}-n_{o}}{n_{S}\left(\frac{n_{H}}{n_{H}}\right)^{2 N}-n_{o}}\right|^{2}
$$

the reflectance in air or free space is then (Al-Dujely, 2000; Macleod, 1986, 2001):

$$
\mathrm{R}=\left|\frac{1-\left(\frac{n_{H}}{n_{L}}\right)^{2 N}\left(\frac{n_{H}{ }^{2}}{n_{s}}\right)}{1+\left(\frac{n_{H}}{n_{L}}\right)^{2 N}\left(\frac{n_{H}}{n_{S}}\right)}\right|^{2}
$$

The reflectivity of the stack increases with the number of layers in the stack and the spectral bandwidth of high reflectance increases with the $n_{H} / n_{L}$ ratio. Multi-layer broad band high reflectance dielectric mirrors are now readily available (Sharma, 2006). The reflectance of such a film depends on the constructive or destructive interference of light reflected at successive boundaries of different layers of the multilayer stack (Kheraj et al., 2008).

High reflectance coating usually consists of alternate quarter-wave layer of materials with high and low indices of refraction $\left(n_{H} l_{H}=n_{L} l_{L}=\frac{\lambda_{0}}{4}\right)$ (Wwillely, 2002). The standard arrangement is to have an odd number of layers, with the high index layer being the first and last layer (Orfanidis, 2010).

\section{Results and Discussion}

We design a computer program using MATLAB version 7 to calculate and optimize the high-reflectivity for different materials (coatings) within near infrared wave. This program depends on refractive index of materials (coating), number of layers and incident angle.

Figures (4) and (5) show that the coating consists of ( $\mathrm{Si}$ ) as high refraction index (3.42) (Farlow \& Boatener, 1997), $\left(\mathrm{MgF}_{2}\right)$ as low refraction index (1.37) (Al-Dujely, 2000) and the substrate (BK7) with the refractive index (1.505) (BK7 used because it has low losses and high stability, Al-Dujely, 2000), for the central wavelength 
$\left(\lambda_{0}=1200 \mathrm{~nm}\right)$. The results are shown in Table 1.

Figures 6 and 7 show that the coating consists of (SbSe) as high refraction index (3.23 (Kohoutek et al., 2009)), (Na3AlF6) as low refraction index (1.35 (Kim \& Hwangbo, 2002)) and the substrate (glass) with the refractive index $\left(1.52\right.$ (Lusk \& Placido, 2005)), for the central wavelength $\left(\lambda_{0}=1200 \mu \mathrm{m}\right)$. The results are shown in Table 2 :

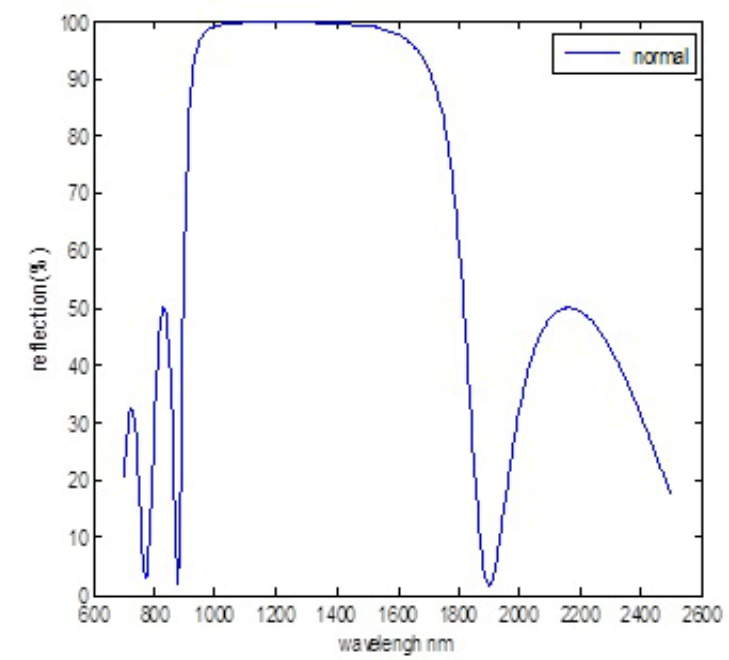

(a)

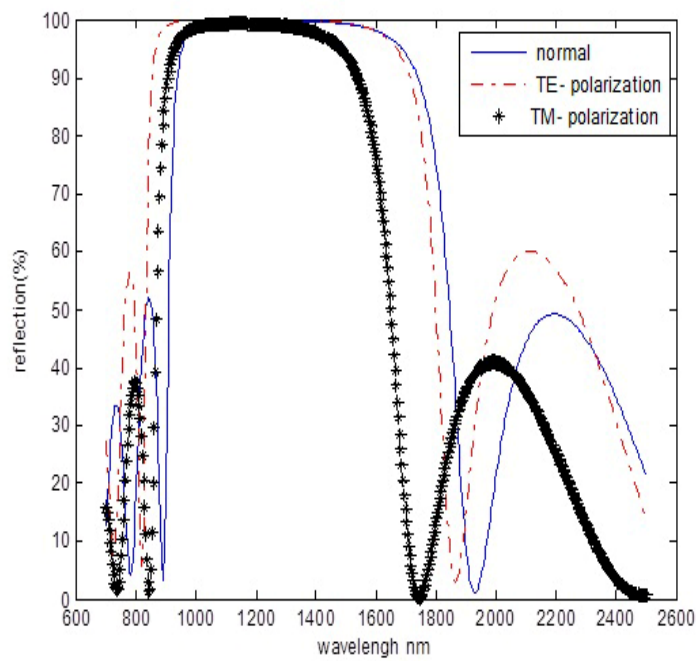

(b)

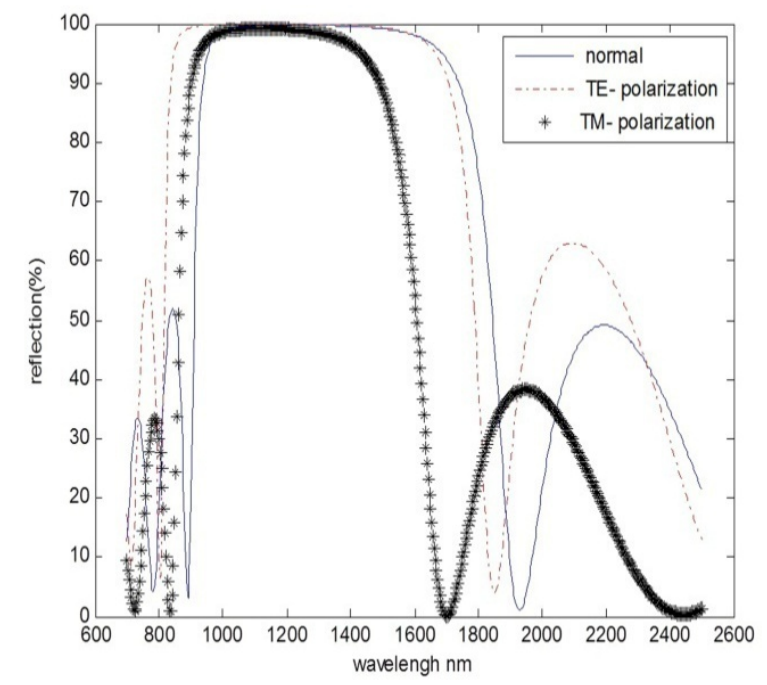

(c)

Figure 4. The Reflectivity as function of wavelength for coating $n(\mathrm{Si})=3.42, n\left(\mathrm{MgF}_{2}\right)=1.37$ and $n(B K 7)=1.505$, for seven layers at incident angle $(\theta)$ of $[\mathrm{a}] 90^{\circ},[\mathrm{b}] 40^{\circ}$ and $[\mathrm{c}] 45^{\circ}$ 


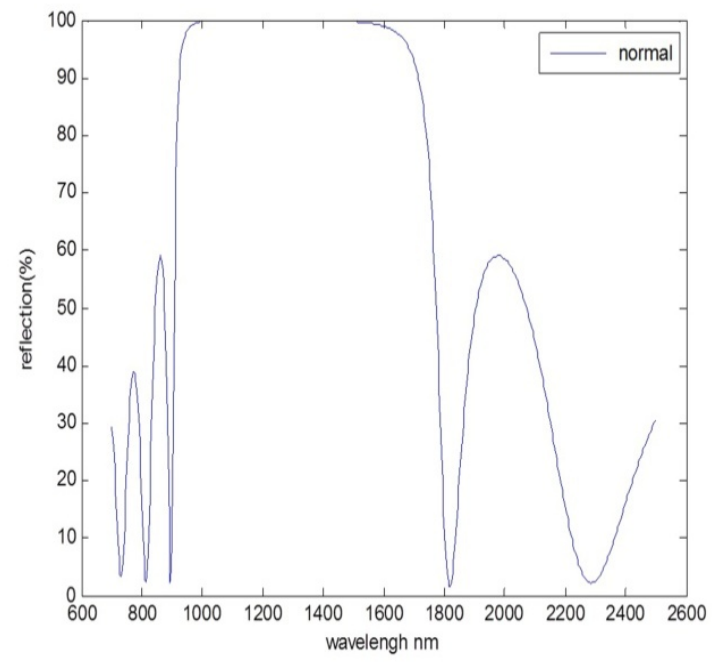

(a)

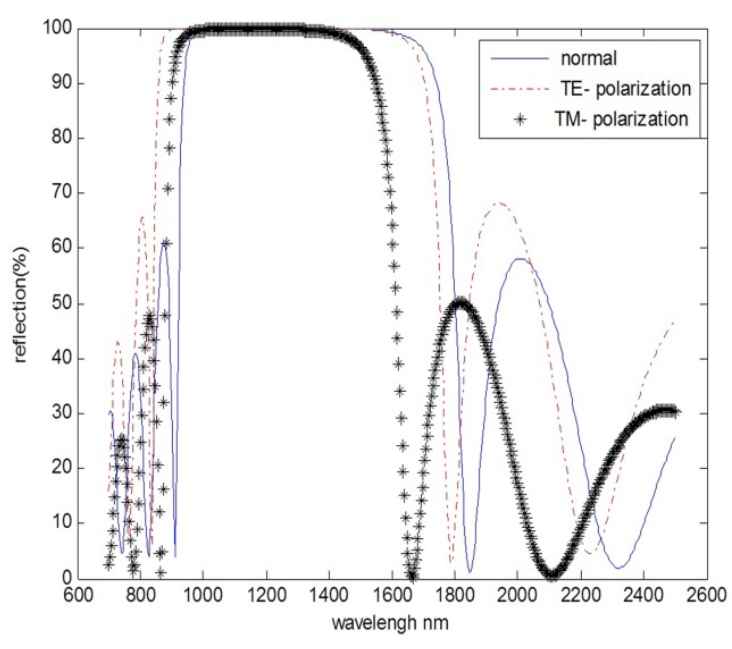

(b)

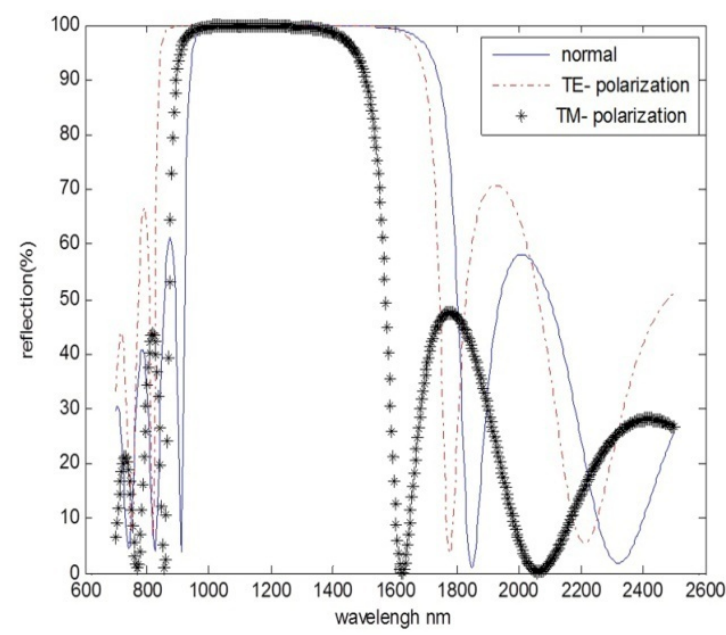

(c)

Figure 5. The Reflectivity as function of wavelength for coating $\mathrm{n}(\mathrm{Si})=3.42, \mathrm{n}(\mathrm{MgF} 2)=1.37$ and $\mathrm{n}(\mathrm{BK} 7)=1.505$, for nine layers at incident angle $(\theta)$ of $[\mathrm{a}] 90^{\circ},[\mathrm{b}] 40^{\circ}$ and [c] $45^{\circ}$ 


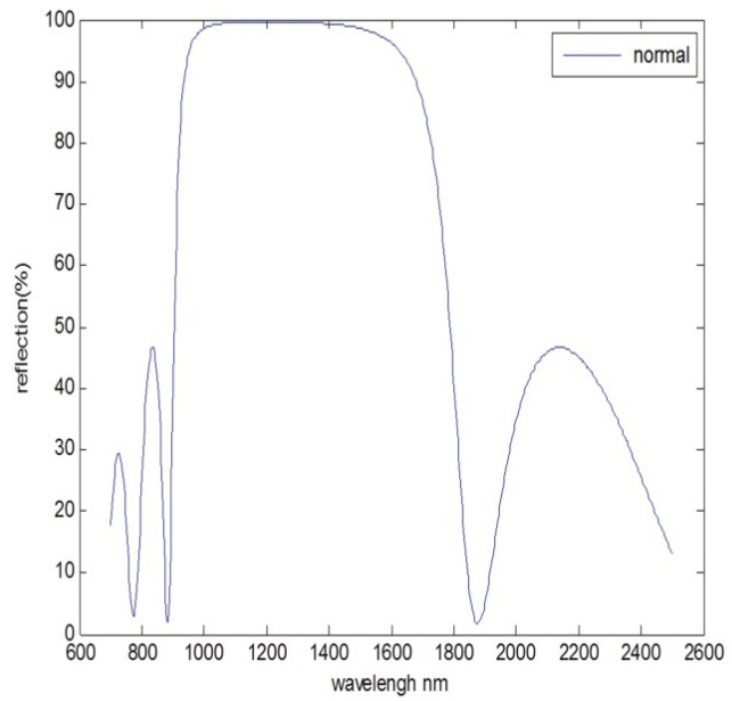

(a)

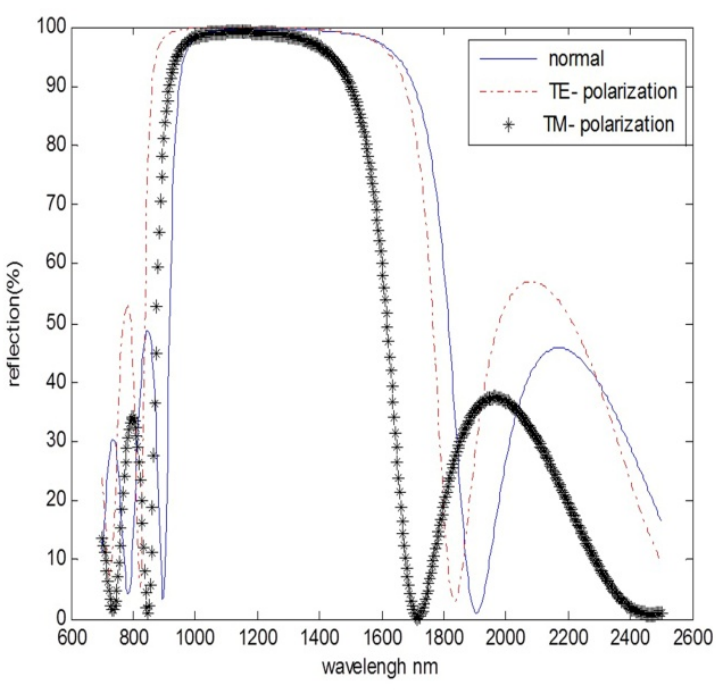

(b)

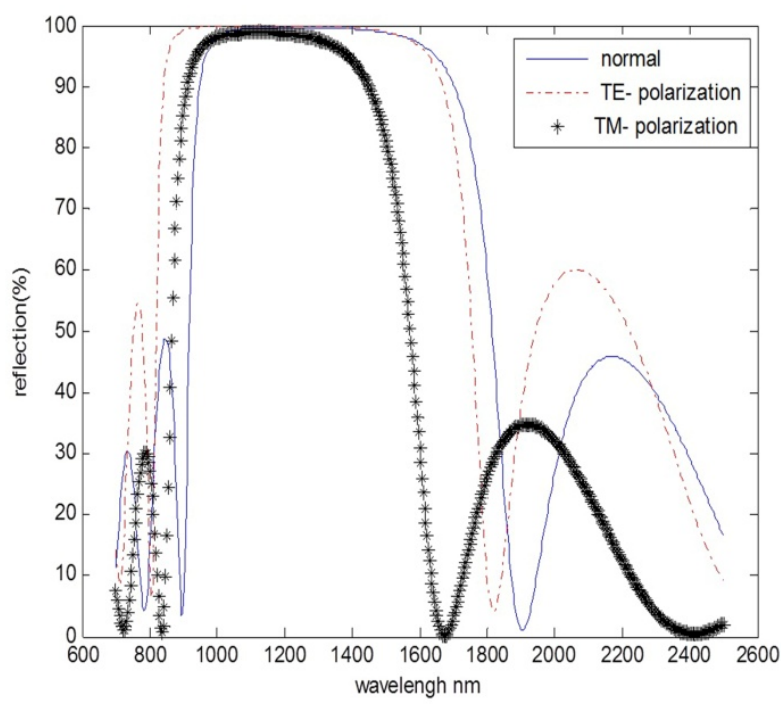

(c)

Figure 6. The Reflectivity as function of wavelength for coating $\mathrm{n}(\mathrm{SbSe})=3.23, \mathrm{n}\left(\mathrm{Na}_{3} \mathrm{AlF} 6\right)=1.35, \mathrm{n}($ glass $)=1.52$, for seven layers at incident angle $(\theta)$ of $[\mathrm{a}] 90^{\circ},[\mathrm{b}] 40^{\circ}$ and $[\mathrm{c}] 45^{\circ}$ 


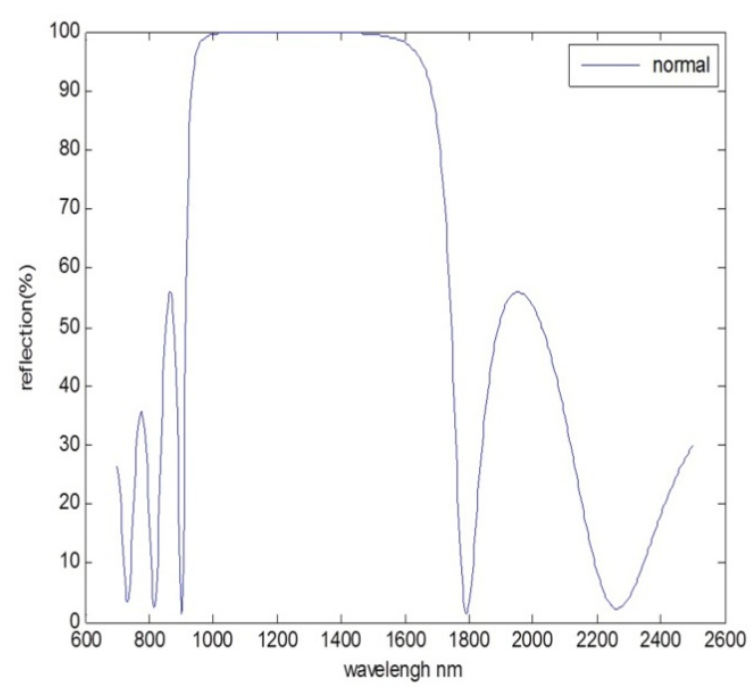

(a)

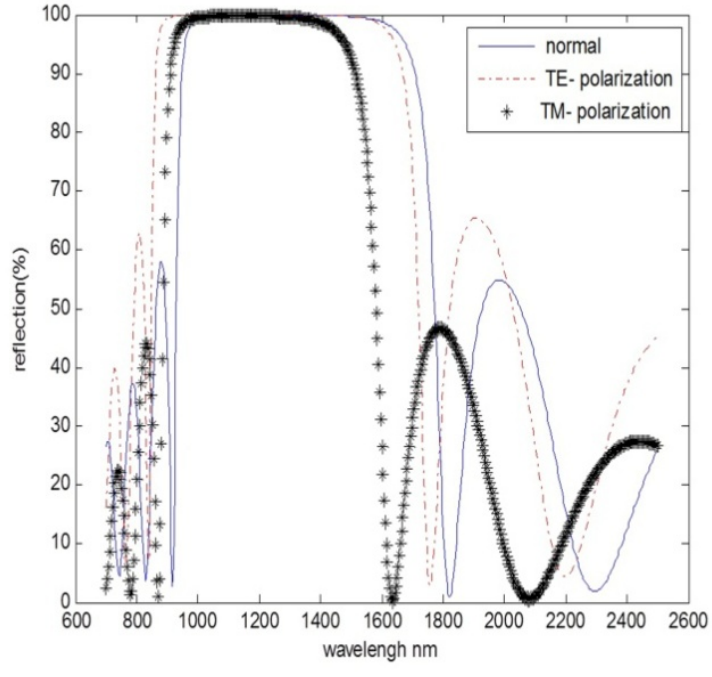

(b)

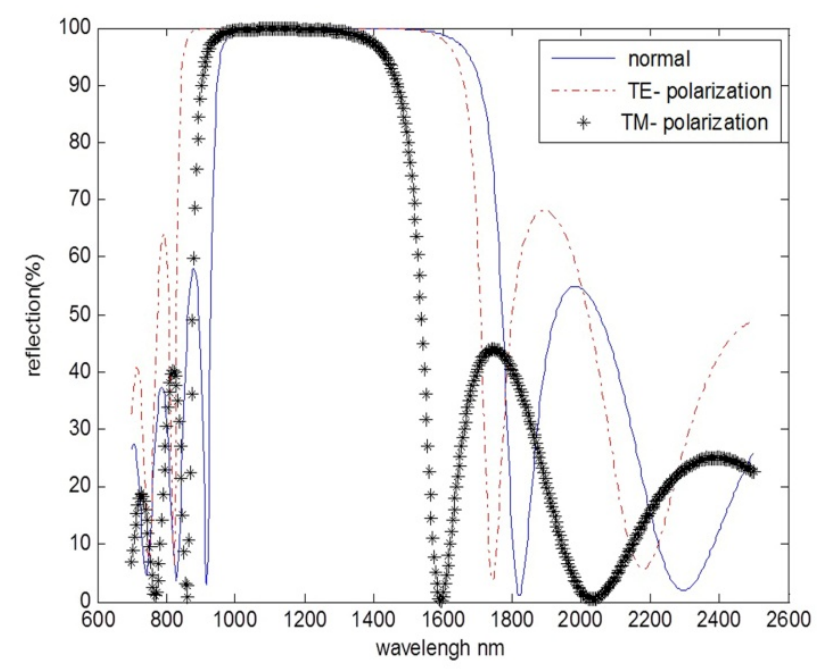

(c)

Figure 7. The Reflectivity as function of wavelength for $\mathrm{n}(\mathrm{SbSe})=3.23, \mathrm{n}\left(\mathrm{Na}_{3} \mathrm{AlF} 6\right)=1.35, \mathrm{n}($ glass $)=1.52$, for nine layers at incident angle $(\theta)$ of $[\mathrm{a}] 90^{\circ}$, [b] $40^{\circ}$ and $[\mathrm{c}] 45^{\circ}$ 


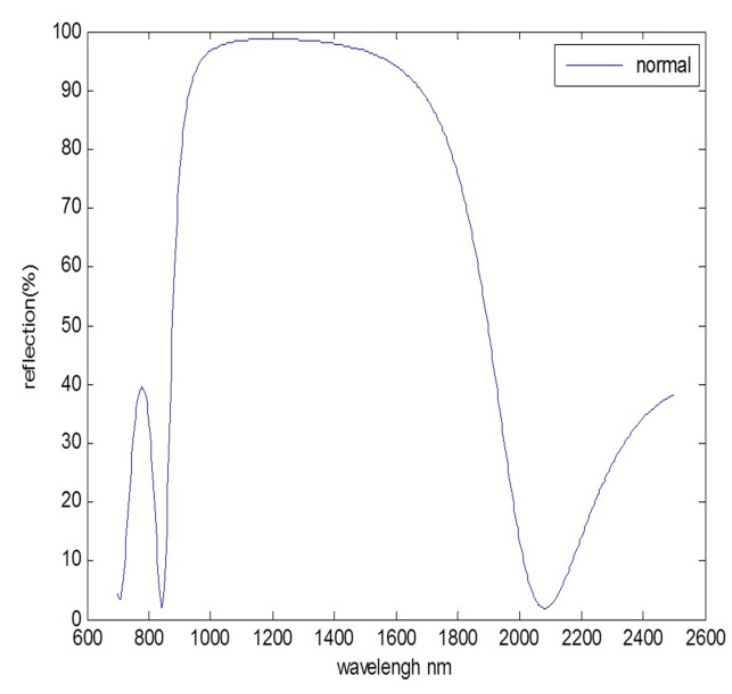

(a)

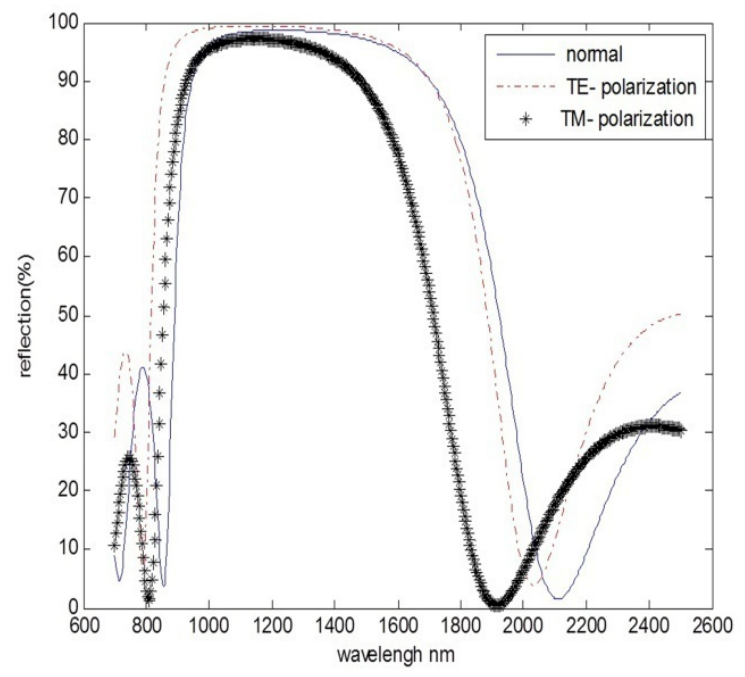

(b)

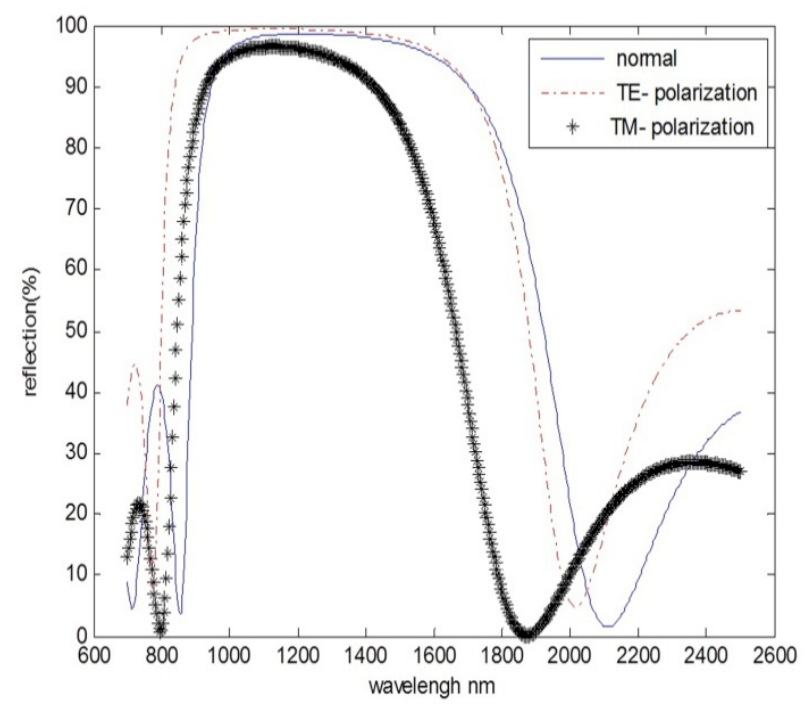

(c)

Figure 8. The Reflectivity as function of wavelength for coating $\mathrm{n}(\mathrm{Si})=3.42, \mathrm{n}(\mathrm{MgF} 2)=1.37$ and $\mathrm{n}(\mathrm{BK} 7)=1.505$, for five layers at incident angle $(\theta)$ of $[\mathrm{a}] 90^{\circ},[\mathrm{b}] 40^{\circ}$ and $[\mathrm{c}] 45^{\circ}$

The reflectivity of (BK7) is $4.064 \%$, and when coating one layer from the $\mathrm{Si}$, the reflective becomes $\mathrm{R}=59.6 \%$, and if one uses three layers [Si MgF2 Si], the reflective becomes $\mathrm{R}=92.07 \%$ at incident angle $\theta=90^{\circ}$ at $\left(\lambda_{\mathrm{o}}=1200 \mathrm{~nm}\right)$. This shows that the reflectivity of the stack increases with the number of layers in the stack, according to equation (16). The spectral bandwidth of high reflectance increases with the $\mathrm{n}_{\mathrm{H}} / \mathrm{n}_{\mathrm{L}}$ ratio (Sharma, 2002). When incident angle $\theta=90$, this reflects that both polarization TE and TM are corresponding.

To obtain a high reflectivity by reducing the number of layers, one can use incident angle as a variable (Kim $\&$ Hwangbo, 2002), as the incident angle increases, the admittance of TE polarization increases and that of TM polarization decreases. So the reflection bandwidth of TE polarization is wider than that at normal incidence, and that of TM polarization is narrower. Therefore, at a high incident angle and reference wavelength, the reflectance of TM-polarized light may be quite low in contrast to the high reflectance of TE-polarized light (Kim \& Hwangbo, 2002). It appears that the best coating is when $\mathrm{R}=99.79 \%$ at incident angle $\theta=90^{\circ}$ and $\mathrm{R}=99.90 \%$ $\mathrm{R}=99.31 \%$ for $\mathrm{TE}, \mathrm{TM}$ respectively at incident angle $\theta=40^{\circ}$ for seven layers for coating $\left(\mathrm{MgF}_{2}, \mathrm{Si}\right.$ and substrate 
BK7), and $\mathrm{R}=99.21 \%, \mathrm{R}=99.13$ for $\mathrm{TE}$, $\mathrm{TM}$ respectively at incident angle $\theta=40^{\circ}$ for nine layers for coating ( $\mathrm{SbSe}$, Na3AlF6 and substrate glass) to obtain the higher reflectivity and lowest number of layers.

As the incident angel increases the center wavelengths of both reflection bands shift to shorter wavelength region as show in Figures 6(b, c) and 7(b, c) in Table (2).This coating which used BK7 as substrate is used in laser applications as coating for the ND:YAG laser $(1060 \mathrm{~nm})$ (Al-Dujely, 2000). In this paper, the reflectivity for the coating was $\mathrm{R}=98.07 \%$ at incident angle $\theta=90^{\circ}, \mathrm{R}=99.31$ for TE and $\mathrm{R}=96.92 \%$ for $\mathrm{TM}, \theta=45^{\circ}, \mathrm{R}=99.45 \%$ for $\mathrm{TE}$ and $\mathrm{R}=96.35 \%$ for $\mathrm{TM}$ for $\mathrm{N}=2$, as shows in Figure $(8 \mathrm{a}, \mathrm{b}, \mathrm{c}$ ) when $\mathrm{N}=3, \mathrm{R}=99.61 \%$ at incident angle $\theta$ $=90^{\circ}, \mathrm{R}=99.91$ for TE and $\mathrm{R}=99.35 \%$ for $\mathrm{TM}$ for $\theta=40^{\circ}$ and when $\theta=45^{\circ} \mathrm{R}=99.93 \%$ for $\mathrm{TE}$ and $\mathrm{R}=99.2 \%$ for $\mathrm{TM}$, as shows in Figure $4(\mathrm{a}, \mathrm{b}, \mathrm{c})$. It appears that the best coating was $\mathrm{R}=99.91 \%, \mathrm{R}=99.35 \%$ at $\theta=90^{\circ}, \theta=40^{\circ}$, respectively for $\mathrm{N}=3$, the best coating was when obtaining the higher reflectivity and lower number of layers, and the best incident angle was $\theta=40^{\circ}$ because the beam attenuation increases with increasing the angle of incidence beyond the critical angle(Sophocles, 2010).

When comparing these results with the results of AL-Dujely Wasfi Hammed Rasheed (2000), who used thin-film $\mathrm{ZnS}, \mathrm{MgF}_{2}$ as coating and $\mathrm{BK} 7$ as the substrate and got the reflectivity $\mathrm{R}=82.5 \%$ at a center wavelength of $1060 \mathrm{~nm}$ in five layers, it seems that the coating one can design when $\mathrm{N}=3$ is the best.

The substrate (glass) which has the reflectivity $\mathrm{R}=4.258 \%$ with the coating ( $\mathrm{SbSe}$ ) and (Na3AlF6) has a reflectivity greater than $98.37 \%$ for the range $(955.6-1622 \mathrm{~nm})$ for $\mathrm{N}=5$ at $\theta=90^{\circ}$ as shows Figure $7(\mathrm{a})$. This coating is used in laser applications and optical communications. So that it covers bands S, C and L for optical telecommunication where (C band is $1530-1560 \mathrm{~nm}$ ), ( $\mathrm{S}$ band is $1460-1530 \mathrm{~nm}$ ) and (L band is $1560-1620 \mathrm{~nm}$ ) (Kim \& Hwangbo, 2002). The coating one can design when $\mathrm{N}=5$ is best compared with that of Kim and Hwangbo used glass as the substrate and $\left(\mathrm{TiO}_{2}, \mathrm{SiO}_{2}\right)$ as coating and obtained a reflectivity greater than $98 \%$ at $\mathrm{TM}, \theta=85^{\circ}, \theta=0^{\circ}$ for $(\mathrm{N}=30$ ) covering the $\mathrm{S}, \mathrm{C}$ and $\mathrm{L}$ from $1286.8 \mathrm{~nm}$ to $1629.1 \mathrm{~nm}$ (Kim \& Hwangbo, 2002).

The reflectivity of (BK7) is $4.064 \%$, and when coating one layer from the $\mathrm{Si}$, the reflective becomes $\mathrm{R}=59.6 \%$, and if one uses three layers $\left[\mathrm{Si} \mathrm{MgF} 2 \mathrm{Si}\right.$ ], the reflective becomes $\mathrm{R}=92.07 \%$ at incident angle $\theta=90^{\circ}$ at $\left(\lambda_{\mathrm{o}}=1200 \mathrm{~nm}\right)$. This shows that the reflectivity of the stack increases with the number of layers in the stack, according to Equation (16). The spectral bandwidth of high reflectance increases with the $\mathrm{n}_{\mathrm{H}} / \mathrm{n}_{\mathrm{L}}$ ratio (Sharma, 2002). When incident angle $\theta=90^{\circ}$, this reflects that both polarization TE and TM are corresponding.

To obtain a high reflectivity by reducing the number of layers, one can use incident angle as a variable (Kim \& Hwangbo, 2002), as the incident angle increases, the admittance of TE polarization increases and that of TM polarization decreases. So the reflection bandwidth of TE polarization is wider than that at normal incidence, and that of TM polarization is narrower. Therefore, at a high incident angle and reference wavelength, the reflectance of TM-polarized light may be quite low in contrast to the high reflectance of TE-polarized light (Kim \& Hwangbo, 2002). It appears that the best coating is when $\mathrm{R}=99.79 \%$ at incident angle $\theta=90^{\circ}$ and $\mathrm{R}=99.90 \%$ $\mathrm{R}=99.31 \%$ for $\mathrm{TE}, \mathrm{TM}$ respectively at incident angle $\theta=40^{\circ}$ for seven layers for coating $\left(\mathrm{MgF}_{2}, \mathrm{Si}\right.$ and substrate BK7), and $\mathrm{R}=99.21 \%, \mathrm{R}=99.13$ for TE, TM respectively at incident angle $\theta=40^{\circ}$ for nine layers for coating ( $\mathrm{SbSe}$, $\mathrm{Na}_{3} \mathrm{AlF}_{6}$ and substrate glass) to obtain the higher reflectivity and lowest number of layers.

As the incident angel increases the center wavelengths of both reflection bands shift to shorter wavelength region as show in Figures $6(b, c)$ and $7(b, c)$ in Table 2. This coating which used BK7 as substrate is used in laser applications as coating for the ND:YAG laser (1060nm) (Al-Dujely, 2000). In this paper, the reflectivity for the coating was $\mathrm{R}=98.07 \%$ at incident angle $\theta=90^{\circ}, \mathrm{R}=99.31$ for $\mathrm{TE}$ and $\mathrm{R}=96.92 \%$ for $\mathrm{TM}, \theta=45^{\circ}, \mathrm{R}=99.45 \%$ for $\mathrm{TE}$ and $\mathrm{R}=96.35 \%$ for $\mathrm{TM}$ for $\mathrm{N}=2$, as shows in Figure $8(\mathrm{a}, \mathrm{b}, \mathrm{c})$ when $\mathrm{N}=3, \mathrm{R}=99.61 \%$ at incident angle $\theta$ $=90^{\circ}, \mathrm{R}=99.91$ for $\mathrm{TE}$ and $\mathrm{R}=99.35 \%$ for $\mathrm{TM}$ for $\theta=40^{\circ}$ and when $\theta=45^{\circ} \mathrm{R}=99.93 \%$ for TE and $\mathrm{R}=99.2 \%$ for $\mathrm{TM}$, as shows in Figure $4(\mathrm{a}, \mathrm{b}, \mathrm{c})$. It appears that the best coating was $\mathrm{R}=99.91 \%, \mathrm{R}=99.35 \%$ at $\theta=90^{\circ}, \theta=40^{\circ}$, respectively for $\mathrm{N}=3$, the best coating was when obtaining the higher reflectivity and lower number of layers, and the best incident angle was $\theta=40^{\circ}$ because the beam attenuation increases with increasing the angle of incidence beyond the critical angle (Sophocles, 2010).

When comparing these results with the results of AL-Dujely Wasfi Hammed Rasheed", 2000, who used thin-film $\mathrm{ZnS}, \mathrm{MgF}_{2}$ as coating and $\mathrm{BK} 7$ as the substrate and got the reflectivity $\mathrm{R}=82.5 \%$ at a center wavelength of $1060 \mathrm{~nm}$ in five layers, it seems that the coating one can design when $\mathrm{N}=3$ is the best.

The substrate (glass) which has the reflectivity $\mathrm{R}=4.258 \%$ with the coating ( $\mathrm{SbSe}$ ) and ( $\mathrm{Na}_{3} \mathrm{AlF}_{6}$ ) has a reflectivity greater than $98.37 \%$ for the range $\left(955.6-1622 \mathrm{~nm}\right.$ ) for $\mathrm{N}=5$ at $\theta=90^{\circ}$ as shows Figure $7 \mathrm{a}$. This coating is used in laser applications and optical communications. So that it covers bands S, C and L for optical telecommunication where (C band is $1530-1560 \mathrm{~nm}$ ), ( $\mathrm{S}$ band is $1460-1530 \mathrm{~nm}$ ) and (L band is $1560-1620 \mathrm{~nm}$ ) (Kim \& Hwangbo, 2002). The coating one can design when $\mathrm{N}=5$ is best compared with that of Kim and 
Hwangbo used glass as the substrate and $\left(\mathrm{TiO}_{2}, \mathrm{SiO}_{2}\right)$ as coating and obtained a reflectivity greater than $98 \%$ at TM, $\theta=85^{\circ}, \theta=0^{\circ}$ for $(\mathrm{N}=30)$ covering the $\mathrm{S}, \mathrm{C}$ and $\mathrm{L}$ from $1286.8 \mathrm{~nm}$ to $1629.1 \mathrm{~nm}$ (Kim \& Hwangbo, 2002).

Table 1. The values of Reflectivity coating $\mathrm{Si}, \mathrm{MgF}_{2}$ of the substrate (BK7) for incident angles $\left(90^{\circ}, 40^{\circ}, 45^{\circ}\right)$

\begin{tabular}{cccc}
\hline $\begin{array}{c}\text { Number of Figure/ and } \\
\text { Number of layers }\end{array}$ & $\begin{array}{c}\text { Incidence } \\
\text { angle }\end{array}$ & $\begin{array}{c}\text { Wavelength } \\
\mathrm{nm}\end{array}$ & $\begin{array}{c}\text { Reflectivity } \\
\mathrm{R}\end{array}$ \\
\hline 4.a / $\mathrm{N}=3$ & $90^{\circ}$ & $1056-1384$ & $\mathrm{R}>99.6 \%$ \\
& & $944.8-1391$ & $\mathrm{R}_{\mathrm{TE}}>99.7$ \\
$4 . \mathrm{b} / \mathrm{N}=3$ & $40^{\circ}$ & $1010-1269$ & $\mathrm{R}_{\mathrm{TM}}>99.04$ \\
& & $923.2-1391$ & $\mathrm{R}_{\mathrm{TE}}>99.72$ \\
4.c / N=3 & $45^{\circ}$ & $980.8-1269$ & $\mathrm{R}_{\mathrm{TM}}>98.57$ \\
5.a / N=4 & $90^{\circ}$ & $1053-1391$ & $\mathrm{R}^{\circ}>99.91$ \\
$5 . \mathrm{b} / \mathrm{N}=4$ & $40^{\circ}$ & $941.2-1391$ & $\mathrm{R}_{\mathrm{TE}}>99.94$ \\
& & $941.2-1391$ & $\mathrm{R}_{\mathrm{TM}}>99.07$ \\
$5 . \mathrm{c} / \mathrm{N}=4$ & $45^{\circ}$ & $916-1391$ & $\mathrm{R}_{\mathrm{TE}}>99.94$ \\
& & $916-1287$ & $\mathrm{R}_{\mathrm{TM}}>98.11$ \\
\hline
\end{tabular}

Table 2. The values of Reflectivity coating SbSe, Na3AlF6 of the substrate (glass) for incident angles $\left(90^{\circ}, 40^{\circ}\right.$, $\left.45^{\circ}\right)$

\begin{tabular}{cccc}
\hline $\begin{array}{c}\text { Number of Figure / and } \\
\text { Number of layers }\end{array}$ & $\begin{array}{c}\text { Incidence } \\
\text { angle }\end{array}$ & $\begin{array}{c}\text { Wavelength } \\
\mathrm{nm}\end{array}$ & $\begin{array}{c}\text { Reflectivity } \\
\mathrm{R}\end{array}$ \\
\hline $6 . \mathrm{a} / \mathrm{N}=4$ & $90^{\circ}$ & $955.6-1622$ & $\mathrm{R}>97.25$ \\
6.b / N=4 & $40^{\circ}$ & $869.2-1578$ & $\mathrm{R}_{\mathrm{TE}}>98.02$ \\
& & $930.4-1406$ & $\mathrm{R}_{\mathrm{TM}}>97.98$ \\
6.c / N=4 & $45^{\circ}$ & $858.4-1539$ & $\mathrm{R}_{\mathrm{TE}}>99.04$ \\
& & $905.2-1406$ & $\mathrm{R}_{\mathrm{TM}}>95.5$ \\
7.a / N=5 & $90^{\circ}$ & $955.6-1622$ & $\mathrm{R}^{\circ}>98.37$ \\
7.b / N=5 & $40^{\circ}$ & $880-1564$ & $\mathrm{R}_{\mathrm{TE}}>99.59$ \\
& & $930.4-1406$ & $\mathrm{R}_{\mathrm{TM}}>99.06$ \\
7.c / N=5 & $45^{\circ}$ & $858.4-1535$ & $\mathrm{R}_{\mathrm{TE}}>99.58$ \\
& & $901.6-1409$ & $\mathrm{R}_{\mathrm{TM}}>96.94$ \\
\hline
\end{tabular}

\section{Conclusion}

From the above result, one can conclude that the reflectivity for coating within near infrared waves (700-2500 $\mathrm{nm}$ ) depending on the coating type, number of layers and angle of incidence. The addition of layers does not affect the width of zone of high reflectance, but increases the reflectivity within. The best coating used in laser applications as coating for the ND:YAG laser $(1060 \mathrm{~nm})$ is $\left(\mathrm{Si}_{,} \mathrm{MgF}_{2}\right)$ on the substrata BK7 which gives the best reflection $\mathrm{R}=99.61 \%$ at $\theta=90^{\circ}, \mathrm{R}=99.91$ for $\mathrm{TE}$ and $\mathrm{R}=99.35 \%$ for $\mathrm{TM}$ for $\theta=40^{\circ}$ at $\mathrm{N}=3$. The best coating used in optical communications is $\left(\mathrm{SbSe}, \mathrm{Na}_{3} \mathrm{AlF}_{6}\right)$ on the substrata which gives the best reflection (greater than $98.37 \%$ ) for the range $(955.6-1622 \mathrm{~nm})$ at $\theta=90^{\circ}$ for $\mathrm{N}=5$.

\section{References}

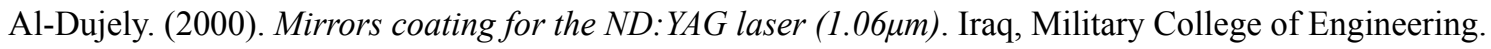

Farlow, G. C., \& Boatener, L. A. (1997). Irradiation effects in MgF2 coating on Si and GaAs substrates. Optical Materials, 8(4), 279-286. http://dx.doi.org/10.1016/S0925-3467(97)00051-7

Finkenthal, D., Greco, B., Halsey, R., Halsey, R., Pena, L., Rodecker, S., ... Schissel, D. P. (1996). Introduction to 
the Electromagnetic Spectrum. The Fusion Education, General Atomics.

Keseibrener, M., \& Ruschin, S. (1999). Interferometric variable reflectivity mirror: experimental results. Optical Materials, 13(1), 97-100. http://dx.doi.org/ 10.1016/S0925-3467(99)00017-8

Kheraj, V. A., Panchal, C. J., Desai, M. S., \& Potbhare, V. ( 2008). Simulation of reflectivity spectrum for non-absorbing multilayer optical thin films. Springer-Verlag. http://dx.doi.org/10.1007/s12043-009-0081-0.

Kohoutek, T., Orave, J., Prikryl, J., Mistrik, J., Wagner, T., \& Frumar, M. (2009). Near infrared quazi-omnidirectional reflector in chalcogenide glasses. Optical Materials, 32, 154-158. http://dx.doi.org/10.1016/j.optmat.2009.07.004.

Li, S. Z., Chu, R. F., Liao, S. C. \& Zhang. L. (2007). Illumination Invariant Face Recognition Using Near-Infrared Images. IEEE T. PAMI, 29(4), 627-639. http://dx.doi.org/10.1109/TPAMI.2007.1014

Lipson, A., Lipson, S. G., Lipson, H., \& FRS. (2010). Optical Physics (4th ed.). New York, NY: Cambridge University Press.

Lusk, D., \& Placido, F. (2005). Omnidirectional mirror coating design for infrared applications. Thin Solid Films, 492, 226-231. http://dx.doi.org/10.1016/j.tsf.2005.06.053

Macleod, H. A. (1986, 2001). Thin-Film Optical Filters (3rd ed.). Physics Publishing, University of Arizona

Michele, R., Derrick, D., \& James, M. L. (1995). Infrared spectroscopy in conservation science. Los Angeles: Getty Conservation Institute.

Sharma, K. K. ( 2006). OPTICS Principles and Applications. Los Angeles: Elsevier Inc. The Getty Conservation Institute.

Sophocles, J. O. (1999-2010). Electromagnetic Waves and Antennas. Rutgers University

Stenzel, O. (2005). The Physics of Thin Film Optical Spectra. Berlin, Heidelberg: Springer. http://dx.doi.org/10.1007/3-540-27905-9

Kim, S. H., \& Hwangbo, C. K. (2002). Design of omnidirectional high reflectors with quarter-wave dielectric stacks for optical telecommunication bands. Applied Optics, 41, 3187-3192. http://dx.doi.org/10.1364/AO.41.003187

Wwillely, R. R. (2002). Practical Design and Production of Optical Thin Films. New York, Basel: Marcel Dekker, Inc. 